\title{
Strategies of food detection in a captive cathemeral lemur, Eulemur rubriventer
}

\author{
Mats Perrenoud $^{1}$, Anthony Herrel ${ }^{1}$, Antony Borel ${ }^{2,3}$ \& Emmanuelle Pouydebat ${ }^{1, *}$
}

1 UMR 7179 C.N.R.S/M.N.H.N., Département d'Ecologie et de Gestion de la Biodiversité, 57 rue Cuvier, Case postale 55, 75231, Paris Cedex 5, France.

2 Institute of Archaeological Sciences, Eötvös Loránd University, Budapest, Hungary.

3 Department of Prehistory, UMR 7194-CNRS/ National Museum of Natural History, Paris, France.

* Corresponding author: epouydebat@mnhn.fr

\begin{abstract}
The senses involved in food detection in primates in general, and lemurs in particular, remain poorly investigated. However, as lemurs include diurnal, nocturnal, and cathemeral species they represent a good model to test whether prey detection is dependent on activity pattern. As both diurnal and nocturnal species have been investigated previously we here aim to quantify the relative importance of different sensory modalities during prey detection in a cathemeral species, the red-bellied lemur (Eulemeur rubriventer). A series of experiments was performed using a group of four Eulemur rubriventer (Zoo de La Londe les Maures, France) to test the role of visual, olfactory and acoustic cues in prey detection. Both unimodal and multimodal cues were tested. The responses obtained in the different experiments show that visual cues are essential for prey detection in this species, at least in captivity. However, the use of multiple sensory modalities improves the success of detection suggesting that cathemeral species may benefit from the use of multiple sensory modalities.
\end{abstract}

KEY words: food detection, visual cues, cathemeral species, Eulemur rubriventer.

\section{INTRODUCTION}

The sensory modalities used during food detection in primates, and in lemurs in particular, have been poorly investigated (but see ERICKSON 1991, 1994; ERICKSON et al. 1998; BiCCA-MARQUES \& GARBER 2004; GOERLITZ \& SiEMERS 2007; Siemers et al. 2007, PiEP et al. 2008). As lemurs include diurnal, nocturnal, and cathemeral species, they represent a good model to test the effect of activity pattern on prey detection. Whereas diurnal and nocturnal species have been studied previously (e.g. PIEP et al. 2008), little is known about the senses that guide food detection in cathemeral species. Here, we aim to quantify the involvement of the different sensory systems during prey detection in a cathemeral lemur, the red-bellied lemur (Eulemeur rubriventer), a species that forages at dusk to find fruits and insects. As this species forages at dusk we hypothesize that they preferentially use vision and potentially olfaction for food detection (SIEMERS et al. 2007). The large eye size and visual acuity of lemurs suggests that the contribution of the visual system in food detection and prey capture success may indeed depend on daily activity patterns (Ross \& KIRK 2006). However, the pronounced use of olfactory markings and communication by growls (MITTERMEIER et al. 2006) in this species suggests high sensitivity to sounds and odours, and leads us to predict that olfactory and acoustic cues may also be used in food detection. Although the structure and the function of acoustic signals in primates have been previously investigated, only a handful of studies have explored the way that primates hear and use these stimuli (RAMSIER \& DOMINY 2010). Interestingly, it appears that the amplitude of sounds emitted by insects can inform nocturnal lemurs, such as the mouse lemur, on the size and mass of their prey (GOERLITZ \& SIEMERS 2007).

Surprisingly, no sensory detection studies have been performed with members of the Lemuridae rendering our understanding about the evolution of sensory modalities in response to activity patterns in primates limited. Here we experimentally test, 
for one captive species of cathemeral lemur, which sensory modalities affect prey capture success, and discuss the use of sensory cues in relation to activity patterns in primates.

\section{MATERIALS AND METHODS}

\section{Animals and Housing}

The red-bellied lemur (Eulemur rubriventer) is an exclusively arboreal species that lives in the rainforests of eastern Madagascar. In this study, a group of six captive individuals, five males (M) and one female (F) of the tropical zoo of La Londe les Maures (France) were observed; four were used in the experiments. Of these three were males and one was a female. Given that only a single female was used, we could not test for differences between sexes. This will have to be investigated using more individuals in future research.

The placement of the boxes was random and placement was decided using a random number generator implemented in $\mathrm{R}$.

\section{Behavioural Experiments}

The prey used during our trials consisted of crickets as they allowed us to differentiate between the three types of sensory modalities. Red-bellied lemurs were isolated and placed in front of a pair of boxes with a prey placed randomly in one of them. The individual's response was noted as positive if the box containing the prey was opened and as negative if the empty box was chosen. For every test, two habituation trials were performed before the real experiment. Four boxes $(17 \times 20 \times 15 \mathrm{~cm})$ were made and covered by a thick plastic cover slightly longer than the box, which facilitated its opening by the lemurs (Fig. 1). Two boxes were opaque and two were transparent. The boxes were cleaned every day with bleach to avoid any olfactory bias. Three parameters were tested: visual, olfactory and acoustic cues. Their effect was tested in unimodal and multimodal conditions: vision, olfaction, audition, visionolfaction, vision-audition, olfaction-audition. A control experiment with all cues present was also conducted. The seven experiments are summarized in Table 1.

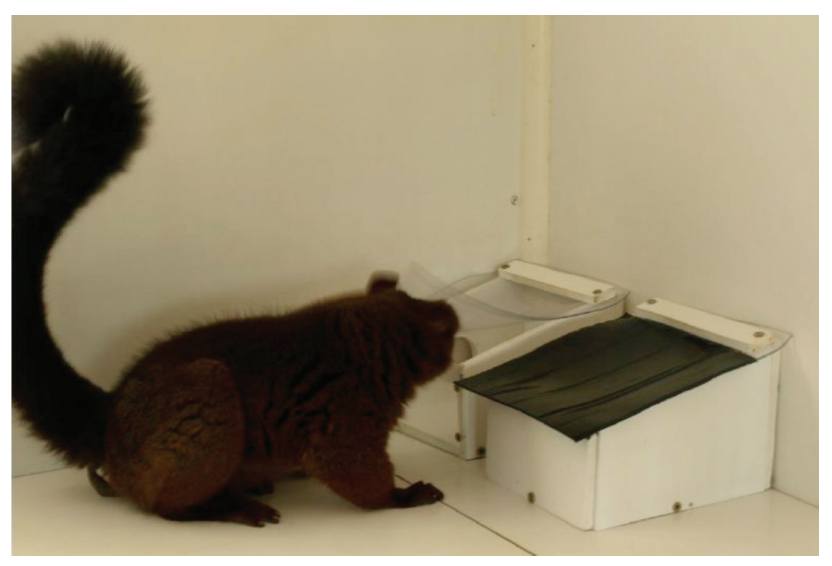

Fig. 1 - Opening of a box by a test subject. The use of an opaque versus transparent lid allowed us to test for the use of visual cues.

To test the use of visual stimuli (V), the pair of boxes was opaque or transparent and crickets were dead and contained in sealed plastic bags to avoid olfactory and auditory stimuli. To test the use of olfaction $(\mathrm{O})$, dead crickets were placed directly in the opaque box or in a transparent hermetically sealed plastic bag that was then put in the box. To test the effect of auditory stimuli (A), live crickets that were moving (and thus making sounds) were placed in one of the opaque boxes in sealed bags, whereas the other box contained dead crickets, also in sealed bags to avoid olfactory stimuli. Seven different experiments were performed with each individual, with four replicates for each experiment, one replicate representing a session of 10 crickets (10 individual responses). Altogether, 1120 responses were analysed (280 responses per individual).

\section{Statistical analyses}

All analyses were performed using R ( R Development Core Team, 2011). Mac Nemar 
TABLE 1

Testing protocol for the different cues. $\mathrm{VOA}=$ vision-olfaction-audition, $\mathrm{AO}=$ audition-olfaction, $\mathrm{VO}=$ visionolfaction, $\mathrm{VA}=$ vision-audition, $\mathrm{O}=$ olfaction, $\mathrm{A}=$ audition, $\mathrm{V}=$ vision.

\begin{tabular}{|cccc|}
\hline Sensory modalities & Box type & Prey status & Prey conditioning \\
\hline VOA & Transparent & Alive & Free \\
AO & Opaque & Alive & Free \\
VO & Transparent & Dead & Free \\
VA & Transparent & Alive & Locked (bag) \\
A & Opaque & Alive & Locked (bag) \\
O & Opaque & Dead & Free \\
V & Transparent & Dead & Locked (bag) \\
\hline
\end{tabular}

tests (comparison of proportions for dependent series) were used to test if there was learning during the detection experiments. We compared the proportions of successful detections during each half of each experiment for each individual and each parameter. This test is used to treat two qualitative variables in two classes (positive/negative response and $1^{\text {st }} / 2^{\text {nd }}$ part of the experiment). The chance factor was tested to verify if the response was random or not. The observed proportions were compared with theoretical proportions (50\% of success) by means of a binomial test (e.g. MiLlot 2009). Tests were performed for each situation at the individual and group level. Finally, to test the effect of the availability of one or several sensory modalities on the proportion of successful detections a G-test with multiple comparisons was performed. A Holm correction was applied to the p-values to take in account the multiple pairwise comparisons (e.g. MiLlOT 2009).

\section{RESULTS}

The Mac Nemar tests showed that no learning was apparent for any of the individuals during the experiment (Table 2).

Moreover, the binomial tests showed that the responses were not random at the group level when visual cues were available (Table $3)$. The situations involving audition, olfaction and audition-olfaction did not give responses diverging from chance. The same results were obtained at the individual level but the responses of one individual (Ernest) were also significantly different from chance when olfaction was available as a unimodal cue.

TABLE 2

Comparison of the proportions of successful detections for each subject according to the available senses. $P$-values for Mac Nemar tests ( $w i t h \mathrm{df}=1$ ). VOA = vision-olfaction-audition, $\mathrm{AO}=$ audition-olfaction, $\mathrm{VO}=$ vision-olfaction, $\mathrm{VA}=$ vision-audition, $\mathrm{O}=$ olfaction, $\mathrm{A}=$ audition, $\mathrm{V}=$ vision.

\begin{tabular}{|lccccccc|}
\hline Individual & VOA & AO & VO & VA & O & A & V \\
\hline Ernest & 1 & 1 & 0.13 & 1 & 0.75 & 0.72 & 1 \\
Bart & 1 & 0.75 & 1 & 0.505 & 1 & 0.55 & 1 \\
Jumpy & 1 & 1 & 0.07 & 0.72 & 0.1 & 1 & 0.37 \\
Pimousse & 0.37 & 0.72 & 1 & 1 & 1 & 0.29 & 0.22 \\
\hline
\end{tabular}


TABLE 3

Comparison of the proportions of successful detections with the theoretical proportions corresponding to a performance level expected by chance. $P$-values for Binomial tests (with $\mathrm{df}=1) . *$ significant values, VOA $=$ vision-olfaction-audition, $\mathrm{AO}=$ audition-olfaction, $\mathrm{VO}=$ vision-olfaction, $\mathrm{VA}=$ vision-audition, $\mathrm{O}=$ olfaction, $\mathrm{A}=$ audition, $\mathrm{V}=$ vision.

\begin{tabular}{|lccccccc|}
\hline Individual & $\mathbf{A}$ & $\mathbf{O}$ & $\mathbf{V}$ & $\mathbf{A O}$ & $\mathbf{V A}$ & VO & VOA \\
\hline Bart & 0.87 & 0.87 & $3.21 \mathrm{e}-03^{*}$ & 0.13 & $1.92 \mathrm{e}-02^{*}$ & $9.28 \mathrm{e}-08^{*}$ & $6.91 \mathrm{e}-07^{*}$ \\
Ernest & 0.99 & $0.01 *$ & $3.21 \mathrm{e}-03^{*}$ & 0.44 & $6.91 \mathrm{e}-07^{*}$ & $9.28 \mathrm{e}-08^{*}$ & $3.39 \mathrm{e}-04^{*}$ \\
Jumpy & 0.92 & 0.68 & $3.39 \mathrm{e}-04^{*}$ & 0.13 & $9.11 \mathrm{e}-05^{*}$ & $2.11 \mathrm{e}-05^{*}$ & $6.91 \mathrm{e}-07^{*}$ \\
Pimousse & 0.56 & 0.68 & $4.18 \mathrm{e}-06^{*}$ & 0.98 & $6.91 \mathrm{e}-07^{*}$ & $3.73 \mathrm{e}-11^{*}$ & $6.91 \mathrm{e}-07^{*}$ \\
Group level & 0.99 & 0.35 & $2.73 \mathrm{e}-12^{*}$ & 0.35 & $1.03 \mathrm{e}-15^{*}$ & $3.12 \mathrm{e}-27^{*}$ & $1.72 \mathrm{e}-20^{*}$ \\
\hline
\end{tabular}

In order to visualize the role of each sensory modality, the averages of the proportions of successful detection for each unimodal and multimodal task were calculated, and are presented in Figure 2.

The worst performance of the lemurs was recorded when only audition was available (40 $\%$ of successful responses). The situations where the olfaction $(\mathrm{O})$ and audition-olfaction (AO) parameters were involved resulted in success rates slightly higher than $50 \%$. In the four other situations (V, VA, VO, VAO), those in which visual cues were involved, more than $75 \%$ of the responses were correct. Vision thus seems to be the dominant sense used in prey detection for this species ( $77 \%$ of correct responses for unimodal experiments involving vision). The results also show that the association of vision with other senses improves the detection performance and thus the access to food. The best performance was recorded when both vision and olfaction were available (90\% of correct responses). The addition of audition to these two modalities reduced the performance of the lemurs $(85 \%$ of correct responses). Moreover, if vision was associated with audition only, the performance decreased to $80 \%$.

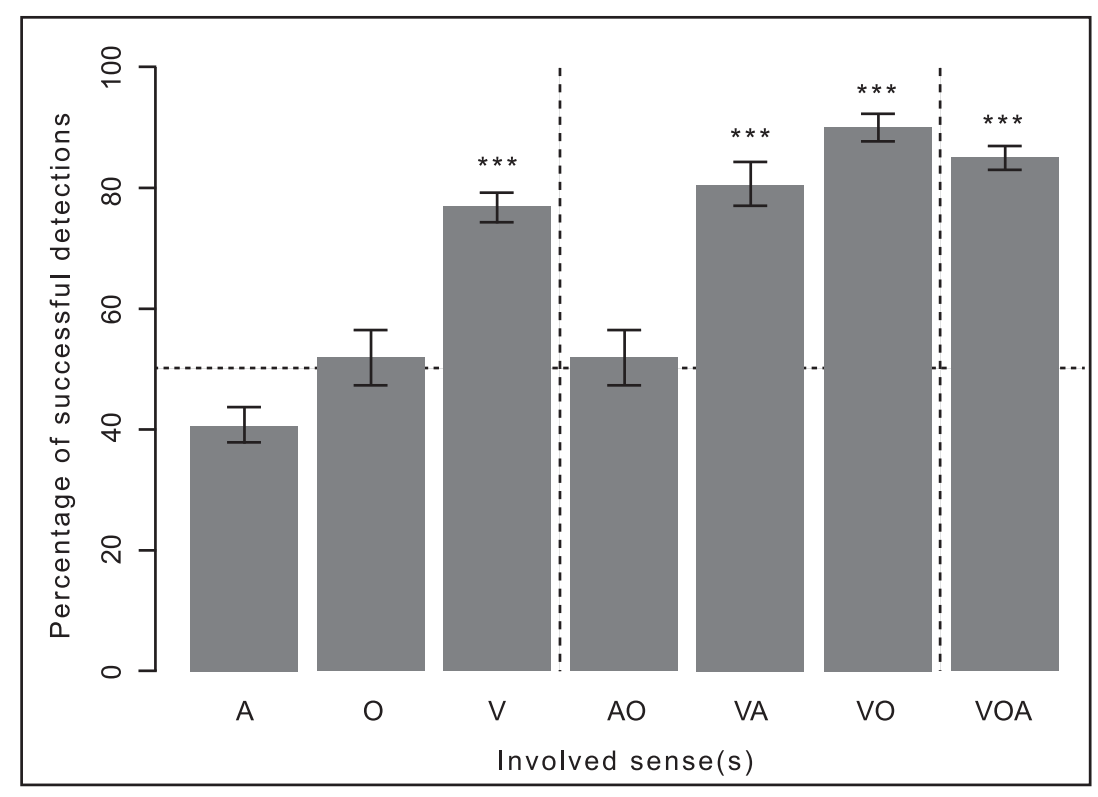

Fig. 2 - Averages of the success proportions of all the subjects $(\mathrm{N}=4)$ for each sensory modality tested with standard errors. ${ }^{* * *}=$ significantly different from chance, $\mathrm{VOA}=$ vision-olfaction-audition, $\mathrm{AO}=$ auditionolfaction, $\mathrm{VO}=$ vision-olfaction, $\mathrm{VA}=$ vision-audition, $\mathrm{O}=$ olfaction, $\mathrm{A}=$ audition, $\mathrm{V}=$ vision. 
TABLE 4

Significance of the difference of the proportion of successful detections according to the available modalities associated with vision. $P$-values of G-tests with multiple comparisons and Holm corrections. ${ }^{*}=$ significant results $(p<0.05), \mathrm{VOA}=$ vision-olfaction-audition, $\mathrm{VO}=$ vision-olfaction, $\mathrm{VA}=$ vision-audition, $\mathrm{V}=$ vision.

\begin{tabular}{|ccc|}
\hline $\begin{array}{c}\text { Available } \\
\text { modalities 1 }\end{array}$ & $\begin{array}{c}\text { Available } \\
\text { modalities 2 }\end{array}$ & $\begin{array}{c}\text { p-values } \\
\text { with Holm correction }\end{array}$ \\
\hline V & VA & 0.60 \\
V & VO & $0.01^{*}$ \\
V & VOA & 0.25 \\
VA & VO & 0.08 \\
VA & VOA & 0.60 \\
VO & VOA & 0.52 \\
\hline
\end{tabular}

To test the significance of the effect of the sensory modalities available (in unimodal and multimodal tasks) on the rate of positive response of the subjects, a G-test on the results concerning only the situations with responses different from those expected by chance at the group level was performed. It gave significant results $(\mathrm{G}=11.33$; df: $3 ; \mathrm{P}=0.01)$. To understand which modality or association of modalities had an effect on performance, differences were tested using a G-test with multiple comparisons and Holm correction, the results of which are presented in Table 4.

Results from the experiment with all cues available (VOA) were not significantly different ( $p$ $>0.05$ ) from the other situations (vision-audition, vision-olfaction and vision) in terms of the proportion of correct responses. The same results were obtained with the bi-modal tasks involving vision and audition $(\mathrm{p}>0.05)$. Nevertheless, a significant difference of performance existed between experiments with visual and olfactory cues and those with only visual cues $(\mathrm{p}<0.05)$. Vision combined with olfaction improved the detection performance compared to situations where only visual cues were available. Therefore, both vision and olfaction are important in prey detection for Eulemur rubriventer.

\section{DISCUSSION}

The objective of this study was to explore the sensory modalities employed by a cathemeral captive lemur to detect insect prey. The captive environment of the species, the relatively simple testing conditions, and the low variability in the food offered (crickets only) could have led to habituation and learning by the lemurs (DUKAS \& KAMIL 2001). However, our results showed that no bias or learning effect could be detected. The statistical analyses also revealed a better detection performance when vision was involved and that these responses were different from chance. In the absence of visual cues, the responses were not different from what could be expected by chance, however. The use of vision in prey detection appears essential but detection performance is improved with the availability of other sensory cues. The data obtained for wild (SIEMERS et al. 2007) and captive (PIEP et al. 2008) mouse lemurs offer similar results concerning the dominance of vision in the detection of prey by lemurs. Yet, it should be noted that our sample size was limited (four individuals) and may thus potentially be biased at the individual level. Thus further experiments using additional individuals would be needed to confirm our results.

\section{Visual parameters}

Visual stimuli appear to dominate prey detection in this lemur species in captivity. A protocol allowing the assessment of sensory 
stimuli involved in prey detection in wild conditions would be interesting to validate our results for captive animals. Previous studies predicted the dominance of visual cues in prey detection in lemurs and highlighted the importance of movement in the detection of prey (CARTMILL 1972, 1974, 1992). In the present study, movement was not tested, similar to the conditions in PIEP et al. (2008). Indeed, in the condition without auditory cues prey were dead to avoid rustling. Therefore, it would be interesting to test detection performance in the presence of moving prey.

\section{Audition}

Crickets were chosen as these insects are very mobile thus favouring the emission of rustling sounds. Whereas olfactory and visual cues remained stable during the tests, acoustic cues could have been variable due to the fact that insects stopped moving once placed in the experimental boxes. Thus, we could have underestimated the detection performance based on auditory cues due to behavioural variability of the prey. Indeed, the study conducted in the wild on Microcebus murinus (GOERLITZ \& SIEMERS 2007) suggests a higher acoustic detection performance than observed here. This discrepancy can potentially be explained by the presence of leaf litter in natural conditions producing more noise upon movement of insect prey, thus aiding acoustic detection. Similarly, many bats depend on the vegetation to detect their prey by echolocation, even if some of them, such as M. bechsteinii and M. myotis, use passive listening to detect their prey via the noise the insects themselves produce (e.g. fluttering sound in moths) and the noise that is made by the insects when touching vegetation (e.g. rustling sound produced when beetles walk over substrate or moths touching leaves with their wing) (SIEMERS \& SWIFT 2006). In addition, for bat species using only echolocation to detect prey (e.g. $M$. nattereri) the vegetation is rather hindering because it produces lots of echoes in which the echo of the prey can be embedded (backward masking effect). These bat species adapt their echolocation calls in a way to better deal with the problem of backward masking (e.g. calls of broad bandwidth, short duration). In primates, studies performed on Tarsiers and Galagos also demonstrated the importance of audition in these nocturnal insectivorous predators (DOYLE 1974; NIEMITZ 1979). Eulemur rubriventer is a species for which social communication involving growls is important (MITTERMEIER et al. 2006). The use of these sounds during communication could potentially also interfere with the acoustic cues emitted by potential prey. Finally, nocturnal species may be more dependent on auditory cues than diurnal or cathemeral species, yet this remains to be tested explicitly.

\section{Olfactory cues}

Diet likely has a significant effect on the cues used in food detection in lemuriforms. Indeed, a similar experiment performed with mouse lemurs and using pieces of fruit instead of live prey demonstrated higher detection performance using olfaction (SIEMERS et al. 2007) than we observed in red-bellied lemur. Frugivorous lemurs are likely more sensitive to smells derived from fruits than from insects, and thus it would be important to perform a similar experiment using fruits. Field observations showed that slender loris (Loris tardigradus) use olfaction to detect insects emitting strongly smelling repulsive substances (NEKARIS 2005). Thus, olfaction in addition to vision may be used by the red-bellied lemur in order to detect strongly smelling toxic prey such as millipeds, which they appear to like (MitTERMEIER et al. 2006).

\section{CONCLUSIONS}

Although our results suggest a dominant role of vision in prey detection in a cathemeral lemur species, a comparison with other primates differing in their daily activity cycle and utilising similar dietary resources is needed to test the generality of these results. Moreover, more 
comparative data are needed to gain insights into the evolution of prey detection in primates.

\section{ACKNOWLEDGEMENTS}

We would like to thanks Jean Michel Dupuyo, the curator of the Tropical Garden of La Londe les Maures (France) and all his staff for their advice and assistance. We also want to thank Elodie Reghem for her help during experiments.

\section{REFERENCES}

Bicca-Marques JC \& Garber PA (2004). Use of spatial, visual and olfactory information during foraging in wild nocturnal and diurnal anthropoids: a field experiment comparing Aotus, Callicebus, and Saguinus. American Journal of Primatology, 62:171-187.

CARTMILl M (1972). Arboreal adaptations and the origin of the order Primates. The Functional and Evolutionary Biology of the Primates:97-122.

CARTMILL M (1974). Rethinking primate origins. Science, 184:436-443.

CARTMILL M (1992). New views on primate origins. Evolutionary Anthropology, 1:105-111.

DOYLE GA (1974). Behavior of prosimians. Behavior of Nonhuman Primates, New York Academic Press:155-353.

DUKAS R \& KAMIL AC (2001). Limited attention: the constraint underlying search image. Behavioral Ecology, 12:192-199.

ERICKSON CJ (1991). Percussive foraging in the aye-aye, Daubentonia madagascarensis. Animal Behaviour, 41:793-801.

ERICKSON CJ (1994). Tap-scanning and extractive foraging in aye-ayes, Daubentonia madagascarensis. Folia Primatologica, 62:125-135.

ERICKSON CJ, NOWICKI S, DOLlar L \& GOEHRING N (1998). Percussive foraging: stimuli for prey location by aye-ayes (Daubentonia madagascarensis). International Journal of Primatology, 19:111-122.

Goerlitz HR \& Siemers BM (2007). Sensory ecology of prey rustling sounds: acoustical features and their classification by wild grey mouse lemurs. Functional Ecology, 21:143-153.
Millot G (2009). Comprendre et réaliser les tests statistiques à l'aide de R. Editions De Boeck:704.

MitTermeier RA, Konstant WR, HaWkins F, LOUIS EE, LANGRAND O, RATSIMBAZAFY J, RASOLOARISON R, GANZHORN JU, RAJAOBELINA S, TATTERSALl I \& MEYERS DM (2006). Lemurs of Madagascar. $2^{\text {nd }}$ edn. Arlington: Conservation International.

NEKARIS KAI (2005). Foraging behaviour of the slender loris (Loris lydekkerianus lydekkerianus): implications for theories of primate origins. Journal of Human Evolution, 49:289-300.

NiEMiTZ C (1979). Outline of the behavior of Tarsius bancanus. The Study of Prosimian Behavior: New York Academic Press:631-660.

PieP M, Radespiel U, ZimmermanN E, Schmidt S \& SiEMERS BM (2008). The sensory basis of prey detection in captive-born grey mouse lemurs, Microcebus murinus. Animal behaviour, 75:871878.

R Development Core Team (2011). R: A language and environment for statistical computing. $\mathrm{R}$ Foundation for Statistical Computing. Vienna, Austria. ISBN 3-900051-07-0, URL http:// www.R-project.org/.

RAMSIER MA \& DOMINY NJ (2010). A comparison of auditory brainstem responses and behavioral estimates of hearing sensitivity in lemur catta and nycticebus coucang. American Journal of Primatology, 72:217-233.

Ross CF \& KIRK EC (2006). Evolution of eye size and shape in primates. Journal of Human Evolution, 52:294-313.

SiEMERS BM \& GOERLITZ HR, ROBSOMANITRANDRASANA E, PIEP M, RAMANAMANJATO JB, RAKOTONDRAVONY D, RAMILIJAONA O \& GANZHORN JU (2007). Sensory basis of food detection in wild Microcebus murinus. International Journal of Primatology, 28: 291-304.

SiEMERS BM \& SWIFT SM (2006). Differences in sensory ecology contribute to resource partitioning in the bats Myotis bechsteinii and Myotis nattereri. Behavioral Ecology and Sociobiology, 59:373-380.

Received: December 16th, 2013

Accepted: June 14th, 2014

Branch editor: Zjef Pereboom 